Marquette University

e-Publications@Marquette

College of Education Faculty Research and

Publications

Education, College of

$3-2021$

\title{
All Are Welcome Except You: Isolation in a Social Justice Community
}

Jody Jessup-Anger

Courtney Howell

Follow this and additional works at: https://epublications.marquette.edu/edu_fac

Part of the Education Commons 


\title{
All Are Welcome, Except You: Isolation in a Social Justice Community
}

\author{
Jody E. Jessup-Anger Courtney Howell
}

Once considered by researchers to be an innovation in undergraduate education, livinglearning communities (LLCs) exist today on many campuses throughout the US (Inkelas et al., 2018). In these communities, students live together, take part in shared academic experiences, and engage in cocurricular programming designed to enhance their learning (Inkelas \& Soldner, 2011). A growing body of research (Inkelas et al., 2018) illustrates academic and involvement advances for students in LLCs. Overwhelmingly, the published research on LLCs illustrates positive gains, as evidenced by the Association of American Colleges and Universities (AAC\&U, 2007) naming learning communities a research-based high-impact practice.

Despite the positive rhetoric about LLCs, Talburt and Boyles (2005) encouraged researchers to explore the potential of learn- ing communities to alienate students. Drawing on their experience advising a learning community, the authors posited that the normative ideals of these communities may "take on a coercive, prescriptive tone rather than one that describes emerging identifications and purposes" (p. 216), and they encouraged researchers to examine the communities more critically.

We address Talburt and Boyle's (2005) call for critical analysis empirically, through an in-depth exploration of one student, Sandra, who provided evidence contradict the notion that LLCs improve student engagement and outcomes. Sandra, who self-identified as an outcast in a social justice-focused LLC, described painful feelings and experiences of isolation. Through our analysis, we learned about the ways in which she felt isolated within a community intentionally designed to support her.

Jody E. Jessup-Anger is Associate Professor of Educational Policy and Leadership at Marquette University. Courtney Howell is a doctoral student in Sociology at the University of Central Florida. 


\section{METHOD}

\section{Theoretical Framework}

For our larger study, we used a qualitative multiple-case study approach (Yin, 1984) and a constructivist epistemology (Broido \& Manning, 2002). To focus on and make meaning of Sandra's experiences as an outlier case, and because of our desire to reexamine the conventional wisdom regarding LLCs as spaces where students thrive, we used frame analysis. Brandwein (2014) explained that a frame "refers to taken-for-granted assumptions and beliefs" that shape an individual's understanding of reality (p. 285). With a frame analysis researchers reconsider the dominant interpretation of reality in the face of new evidence.

\section{Data Sources}

The data for this article were drawn from a larger dataset exploring 36 students' understandings of social justice and LLC involvement across three social justice communities at three private, Catholic institutions (for details, see Jessup-Anger et al., 2020). We interviewed 11 students from the City University (CU) Social Justice Living-Learning Community (SJLLC). We chose to highlight Sandra's experiences, because her story stood in stark contrast to other students' positive experiences and troubled the prevailing assumptions about LLC environments as high impact. She was the only (self-described) outcast in our sample, so we were curious about her experience and wanted to delve further.

Jessup-Anger conducted three 45-to90-minute interviews with Sandra: the first and second at the end of the Fall and Spring semesters while she lived in the community and the third in the spring a year after she left the community. We also obtained Sandra's application to join the community, which included her expectations for the community and her rationale for joining. Finally, we examined the transcripts from the other 10 SJLLC students in our sample to see if their perspectives might shed any further light on Sandra’s experiences.

\section{Setting}

SJLLC was a sophomore community dedicated to examining issues of social justice at $\mathrm{CU}$, a large, highly residential, private, Catholic university in the Midwest. Students lived on two floors in a residence hall (one all-male and one all-female) and took two 3-credit courses together (a philosophy course in the fall and a theology course in the spring). They also participated in 3 hours of service-learning each week as part of their coursework. Their service-learning placements were self-chosen from a list of agencies provided by the office of service-learning. The assignments varied, but all LLC participants were placed in agencies working with adults, including recent immigrants, seniors, and those living with AIDS. Finally, students self-selected into peer interest groups to raise awareness about social justice issues in their community, including poverty, educational disparities, and environmental issues. At the start of the academic year, students in SJLLC attended an overnight retreat, which was organized by the Office of Residence Life and attended by their RAs and their philosophy instructor. During the retreat they participated in team-building activities, developed a common definition for social justice, and discussed their goals for the academic year.

\section{Trustworthiness and Analysis}

We took several steps to ensure the trustworthiness of the qualitative research process (Creswell, 2007). We transcribed all interview data verbatim and sent a synopsis of each interview back to each participant to ensure accurate representation. We also corroborated 
participants' responses with notes we took while interviewing. Further, we gathered data at different points in time, and we raised inconsistencies in and sought clarification of meaning making with our participants when we heard them. Finally, we discussed our results and meaning making with an inquiry auditor who was familiar with the data.

To begin our analysis, we read through each transcript line by line. Because we were using the transcripts to frame Sandra's experience, we combed through all the transcripts for mentions of her experience. We paid special attention to the places where Sandra felt a sense of isolation, the sources of that isolation, and the impact. Then, we looked for themes in Sandra's feelings of isolation and reflected on how these feelings countered prevailing themes of LLC outcomes (Brandwein, 2014). From our analysis of the transcripts, we drafted a description of the findings and shared them via email with Sandra for refinement. Sandra corroborated the descriptions and mentioned in her email response that her time in the LLC was difficult.

\section{FINDINGS}

Sandra's experience in the community was congruent with neither the prevailing research on LLCs nor with responses from the other participants in our sample from SJLLC. To understand the differences between her experience and prevailing research, we illustrate two sources of isolation she revealed: philosophical isolation and social isolation. We discuss these differences in the context of frame analysis and existing research.

\section{Philosophical Isolation}

Sandra described feeling isolated from other SJLLC students because of differences between her understanding of social justice and theirs. She initially encountered this difference during the SJLLC retreat, during which students engaged in discussion to determine a common definition for social justice. Sandra described acquiescing to others' "more liberal definition of social justice" in the activity, because she did not want to seem rigid and was hopeful that further discussion would take place throughout the year. However, Sandra noted that philosophical differences in understanding social justice remained, with no opportunities in the LLC classes or in the community to engage in critical conversations regarding these differences.

In Sandra's application to SJLLC, she defined social justice as a "deep respect for all life, from the moment of conception to a natural death." In the application, students were asked to choose a social justice issue to focus on for the year; Sandra identified hers as being "'whole life' . . . from the child in the womb, to the child in Darfur, from the embryo and to the elderly." She strived to enact this focus throughout her year in the community. In her first interview, Sandra reported that when applying to the community, and particularly after the retreat, she knew that her ideas about social justice were different from those of her peers:

I knew that I would be different than other people, because I know what social justice means to most other people, and I know I define it in a different way. . . . I thought that I would be able to be in dialogue with these other people and approach these issues and see where we differ, ... but there was no [she pauses] dialogue. ... You care about [social justice] so deeply it's just such a core part of you, you're not really open to discussion.

Although other students were as passionate about social justice and the social justice issues they identified, none wanted to work to advance prolife initiatives, which contributed to Sandra's isolation. Although Sandra pointed 
toward her peers as being unwilling to discuss other concepts of social justice, she also demonstrated an unwillingness to explore others' initiatives; in fact, she contradicted her own definition of social justice by citing AIDS advocacy as an example of a social justice issue that others identified with and she did not care about. When asked how that stance aligned with her definition of social justice, she explained that people with AIDS have agency, whereas embryos do not.

Sandra suspected her political identity was also an isolating force. She described SJLLC as an environment in which most of her peers had worked on political campaigns for progressive candidates and how she felt out of place:

I'm definitely a little bit more conservative. ... Everyone was very outspokenly Democrat and I'm not committed either way, and I'd say I'm probably more a Republican on most issues. A lot of [other SJLLC students] associated that if you're not a Democrat, you're not for social justice, period, so I was like, "Okay. That's great." [spoken with sarcasm]

Even though at the outset the community worked together on a common understanding of social justice, for the rest of the academic year Sandra felt isolated and marginalized in the community. The lack of opportunity for further discussion of differences in their concepts of social justice made it very difficult for Sandra to feel included and valued as a member of the community.

\section{Social Isolation}

Perhaps exacerbated by her differing philosophies, Sandra also felt tremendous social isolation within SJLLC. In addition to what we discussed previously about her application, she also described joining the community to look for friends and good roommates, but instead she found herself isolated from her peers even when she was present with them in activities. She described feeling left out and disconnected from other SJLLC students. In Sandra's first interview, she described trying to connect socially: "I am trying to reach out. ... It's not that they're specifically rejecting me; it's just that they're not reaching out to me. When I'm reaching out to them, they are reaching out to other friends." In a later interview, she expanded on her feelings of isolation, describing how she felt marginalized even when she was with other members of the community:

It would be awkward and hard for me to insert myself into the activities, because every time I would, I'd feel like such an outsider. So, it was kind of like saying, "Oh, come and hang out with us. You can be a sideliner, but we'll welcome you [to be present]."

In our interview during her second semester of participation, Sandra described how the pattern of her reaching out had continued to no avail, leading to a breaking point when she decided to stop reaching out:

From that point [after a last attempt to become connected], it was mostly an understanding that I'm going to live here but I'm not really part of the community, and I'm going to do my own thing and hang out with my own friends.

Sandra's strategy of breaking her social isolation by disengaging from the community weighed heavily on her, but ultimately she deemed it a good decision. Upon leaving the community at the end of the school year, Sandra reflected on her decision to disengage: "It was kind of freeing. It was kind of like, you really, really wanted something and then you realized that it's not what you want." Still, Sandra described her overall experience as painful: "I just felt very alone and isolated in the community. I felt like everyone was very together and cohesive, but I wasn't really a part of it. I was . . . ignored by the program." Sandra's mental health 
suffered while she was in the community. In her second interview, she mentioned starting to take antidepressants. Although she did not attribute her depression solely to her experience in SJLLC, she explained that it exacerbated her problems:

I recently started taking prescription for antidepressants. ... I thought that if I met friends that these things would get better. Because the situation hasn't improved [since joining SJLLC], I'm not able to cope with it without the aid of medication.

Overall, Sandra identified feeling stressed, unhappy, uncomfortable, and upset during her time in the community because of her marginalization.

\section{DISCUSSION AND IMPLICATIONS FOR PRACTICE}

In contrast to prevailing research, which highlights the role of LLCs in promoting an academically and socially supportive climate (Inkelas et al., 2018; Wawrzynski et al., 2009), Sandra's experience was overwhelmingly isolating, both philosophically and socially. Understanding the root of Sandra's predicament as philosophical helps to provide empirical grounding that extends Talburt and Boyles's (2005) caution that LLCs may exacerbate isolation and are not always a good fit for students. As illustrated through Sandra's case, having a different philosophical orientation to an LLC — without the opportunity to engage meaningfully in that difference-is one way that isolation can develop.

Using Brandwein's (2014) frame analysis, it is possible to dissect the disconnect between the current research and Sandra's lived experience. The taken-for-granted assumptions in the research around LLCs suggest that all participants in such communities reap the benefits of these communities. These assumptions include: (a) Mere participation in the community will result in positive outcomes; (b) The presence of an LLC inevitably improves the student experience; and (c) All campuses should create LLCs to see positive student outcomes.

These assumptions encourage institutions to create LLCs for the sake of having a highimpact practice on campus (AAC\&U, 2007). Unfortunately, as this case study illustrates, the counterpoint to these prevailing assumptions is underrepresented in LLC research, which suggests that any LLC is better than no LLC. It is clear from the findings here that LLCs may not, in fact, be in the best interest of all students.

Disrupting current assumptions and recognizing that LLCs are possibly detrimental to some students may result in more attention to learning and engagement outcomes. For an LLC to be successful, participants must feel socially integrated, which means that LLC staff, from administrators to resident assistants, must help to foster cultural norms that are sufficiently broad to include all students. Furthermore, in Sandra's case of isolation, there were philosophical differences that contributed to her lack of belonging. If the definition of the community had been clearer from the start, Sandra might have opted out, thus avoiding a painful social experience. Or, alternatively, if there had been more opportunities to engage across these philosophical differences, Sandra and other students might have connected more deeply around these issues.

One implication of this research for LLC practitioners to consider is the importance of ongoing engagement across differences throughout the academic year-be those differences philosophical, political, or psychosocial. Sandra's experience shows how enduring philosophical and political differences served as a barrier to her integration into the community and reveals that there were few avenues to engage across these differences except at 
the outset of the year. Having formal LLC programming and ongoing, structured, curricular, and cocurricular opportunities to engage across differences in LLC classes may reduce the likelihood of isolation and address the sometimes narrow normative culture described by Talburt and Boyles (2005) and illustrated empirically through Sandra's case.

A second implication of this research is the need to ensure that there are mechanisms for identifying and addressing participants' social isolation throughout the year. Sandra (and others) might have benefitted from an LLC resident assistant, instructor, or other administrator checking in on students to evaluate their social integration within the community; Sandra never mentioned this happening. Further, planning additional organized social and cocurricular activities throughout the year, specifically for LLC students, was warranted. Often LLC practi- tioners organize these activities only at the outset, with the assumption that once students engage in classes and cocurricular activities, the social aspects of the community will happen organically. With research being focused on social aspects as key components in the success of LLCs (Inkelas et al., 2018), additional attention must be paid to developing a positive social environment. As LLCs continue to be mechanisms for student engagement, and ultimately retention, additional research should be focused on students for whom these environments do not work, as there may be lessons in their experiences that ultimately improve these communities for all students.

Correspondence concerning this article should be addressed to Jody E. Jessup-Anger, Department of Educational Policy and Leadership, College of Education, Marquette University, PO Box 1881, Milwaukee, WI 53201-1881; jody.jessup-anger@marquette.edu

\section{REFERENCES}

Association of American Colleges and Universities. (2007). College learning and the new global century [Report]. https://www.aacu .org/sites/default/files/files/LEAP/GlobalCentury_final.pdf

Brandwein, P. (2014). Studying the careers of knowledge claims: A guide. In D. Yanow \& P. Schwartz-Shea (Eds.), Interpretation and method: Empirical research methods and the interpretive turn (2nd ed., pp. 284-299). ME Sharpe.

Broido, E. M., \& Manning, K. (2002). Philosophical foundations and current theoretical perspectives in qualitative research. Journal of College Student Development, 43(4), 434-445.

Creswell, J. W. (2007). Qualitative inquiry and research design: Choosing among five traditions (2nd ed). SAGE.

Jessup-Anger, J. E., Armstrong, M., \& Johnson, B. (2020). The role of social justice living-learning communities (LLCs) in promoting students' understanding of social justice and LLC involvement. Review of Higher Education. 43(2), 837-860.
Inkelas, K. K., Jessup-Anger, J., Benjamin, M., \& Wawrzynski, M. (2018). Living-learning communities that work: A researchbased model for design, delivery, and assessment. Stylus.

Inkelas, K. K., \& Soldner, M. (2011). Undergraduate livinglearning programs and student outcomes. In J. C. Smart \& M. Paulsen (Eds.), Higher education: Handbook of theory and research (Vol. 26, pp. 1-55). Springer.

Talburt, S., \& Boyles, D. (2005). Reconsidering learning communities: Expanding the discourse by challenging the discourse. Journal of General Education, 54(3), 209-236.

Wawrzynski, M. R., Jessup-Anger, J. E., Stolz, K., Helman, C., \& Beaulieu, J. (2009). Exploring students' perceptions of academically based living-learning communities. College Student Affairs Journal, 28(1), 138-158.

Yin, R. (1984). Case study research: Design and methods. SAGE. 